\title{
With Nature and the Outdoors as a Resource:A Case of a One-Footed Elderly Man in a Wheelchair
}

Authors' contribution:

A) conception and design of the study

B) acquisition of data

C) analysis and interpretation of data

D) manuscript preparation

E) obtaining funding

\section{Linn Terese Ramsland}

University of Rome, Italy

ABSTRACT

The older population is a greatly increasing group, and municipalities meet more and more demands regarding the health of elderly people. Ageing results in a loss of mobility and reduced independence, but there are different measures and practices possible that may contribute to maintain independence. By being active, elderly people can prevent disease, reduce disability, and increase wellness. Among these measures, research has discovered that older adults can benefit from contact with nature. This case study presents an old man in a wheelchair and his way of living an independent life despite being physically disabled. Harald is 88 years old and lives in the suburb of Ålesund, a town in Norway. Eight years ago, he had his left leg amputated due to cancer and experienced a long and tough recovery process. Harald's way back to restoring his mobility was highly enhanced by the outdoors and natural surroundings, which helped him to restore his independence. His experience, together with other theoretical findings, calls to our attention that nature is a resource on both the mental and the physical level. People who have access to nearby natural settings are healthier overall than other people. Natural surroundings lead one away from daily life and help one to forget about stress and worry. Natural surroundings make one more relaxed and offer a lot of time to reflect on life.

KEYWORDS Elderly, disability, nature, health promotion, nearby nature

\section{Introduction}

Harald is 88 years old and lives in the suburb of Ålesund, a town in Norway. Eight years ago, Harald had his left leg amputated due to cancer and experienced a long and tough recovery process. Harald's way back to restoring his mobility was highly enhanced by the outdoors and natural surroundings, which helped him to restore his independence. In the following paper I will discuss the relationship between the elderly and the outdoors, with Harald as a starting point. The case illustrates how nature can work as a resource for the growing elderly population.

The older population is a greatly increasing group. By 2030, in Norway and many other European countries, people over 60 years will represent one-third of the population, where the increase is largest among the oldest of the old. This future rise will lead to more responsibility for elders' health care and wellness, and it will imply a major economic challenge for the society (Bergman, 2012). 
Health and disease have biological dimensions. As people age, there is a progressive decline in physiological ability to meet demands that occur over time. The rate of biological ageing is determined by both environmental and genetic background (Adams \& White, 2004). Modern biological theories of ageing in humans are represented by two main categories: program theories and damage or error theories. The program theories imply that ageing follows a biological timetable, which is dependent on changes in gene expression that affects the systems responsible for maintenance, repair, and defense. The damage or error theories underline environmental assaults to living organisms, which develop cumulative damage at various levels as the cause of ageing. Within these main categories, there are several theories that make ageing more understandable. There is no consensus on the issue, but many of the theories of ageing interact with each other in complex ways. Knowledge about the theories and the consequences of ageing is essential to promote successful aging, as well as to enhance lifespan (Jin, 2010).

Ageing results in a loss of mobility and hereby reduced independence. The process of ageing can be affected by several influences that may contribute to maintain independence as well as the quality of life among elderly. Research has suggested that older adults can benefit from contact with nature and the outdoors. This is similar to other age groups, where evidence shows increased satisfaction and reduced physiological and psychological stress (Talbot \& Kaplan, 1991). Our case-person Harald experienced these positive effects derived from contact with nature and the outdoors.

\section{Harald, a life with green nature - and disability}

Despite Harald being an old man in a wheelchair, I spot him frequently outside his house working in the garden or even rowing out his boat for fishing. Our whole neighborhood knows the old man in the wheelchair and admires his way of living as an independent individual. A man who will soon reach 90 years of age, lives alone in his house, and still makes his dinner, even though he is in a wheelchair, is a fantastic case. Curious about his motivation, I asked him about his life, the disease with the following recovery process, and his daily living. He gladly shared his life experience, in which the relationship with nature became clearly evident.

Harald has always spent a lot of time outdoors, surrounded by beautiful nature in the western part of Norway. He is a hardworking man and had an active lifestyle as a farmer and bus driver, two jobs he appreciated a lot. In 1989 Harald had a heart attack and had to go through a coronary artery bypass surgery. To enhance his recovery, he implemented long hunting trips in the mountains as soon as possible after the surgery. Two months later, he was back as a full-time worker. He has no doubt that the mountain trips and outdoors favored his recovery process, which is something he also experienced later on in life.

When Harald was 80 years old, he suffered from a lot of pain in his left hip and foot. The pain turned out to be a big tumor in the hip joint. The doctors told him that if he refrained from doing something with the tumor, he would most likely die within one year, and his only option was to remove the tumor. This was a major surgery with an $80 \%$ chance of survival. The amputation started over the hip, where half of the pelvic bone was removed, and he suffered a reduction of $25 \%$ of his total body weight. After the surgery, Harald had several long treatments with antibiotics as a result of infections and wounds that would not heal. An extended stay at the hospital was followed by two months in the nursing home:

"In this period of life I needed help for everything. The feeling of being completely dependent on others actually made me regret that I went through with the operation. I pictured a life where I was forced to sit inside and wait for the home care assistant and thereafter die in a worthless way. My family tried to encourage me, but I was still struggling to accept the situation. My whole life I had taking care of myself, but now I had to completely depend on others to take care of me. I felt like my dignity was gone”.

While at the nursing home, Harald got a leave for one day to visit his home. He remembers this beautiful Sunday in May as it was yesterday: 
"My family wanted us to stay inside, but I was so tired of dark indoor air and insisted to sit outside. I felt the amazing warmth and energy from the sun. I watched the green meadow blowing gently in the wind. I heard the birds singing, and I could smell the fresh scents of spring in the air. That feeling is the most wonderful thing I have ever experienced. I was moved to tears. The joy of being outside made me a hundred times better than anything else after the surgery, both mental and physical. I returned to the hospital and longed for that beautiful sunny day at home. Still, I was not convinced that I had much time left to live, but the thought of fresh air and nature made me realize that I could actually experience wonderful things again".

\section{Outdoors in Norwegian culture}

For a Norwegian, outdoor life in green nature has a high value. Although the younger population shows less participation in outdoor activities, the elderly and retired people are increasingly active in this field. They spend a lot of time on outdoor activities, and it is highly appreciated to be active in fresh air and untouched nature (Bergman, 2012). According to Lawton (1986), the environment offers three vital functions for the elderly: stimulation, maintenance, and support. These environmental influences can play an important role for older people to stay active and remain independent.

Which of the nature's different components offer the highest health benefit is unknown. Is it the experience of nature itself, physical activity, excitement, calm, sunshine, fresh air, or the social and pedagogic framework? The best positive outcome is most certainly shown as a combination of all these elements (Bischoff, Marcussen, \& Reiten, 2007). According to Kaplan and Kaplan (1989), the environment requires four elements to be restorative: fascination (an involuntary form of attention that requires effortless interest or curiosity); the sense of being away (a temporary escape from usual settings and situations); extent or scope (a sense of being part of a whole); and compatibility with individual inclination (the setting being able to satisfy individuals' purposes). Kaplan and Kaplan also stated that the fantastic thing about the natural environment is that it applies so broadly to humans.

After his stay at the hospital and nursing home, Harald moved back to his now-deceased wife. In the beginning, he felt very unsecure, and the home care assistant came by several times a day to help him with almost everything.

"Even if I was still completely dependent on others, it was nice to finally stay at home and enjoy the fresh air. As time went by, I was so tired of lying in my bed and wait for someone to help me up in the morning, so I started to get up and dress myself. In the beginning, it was quite a struggle, but when I first realized that it was working, everything went in rapid succession. Today I get up and dress whenever I want, and also, I take shower once a week without help. I can go outdoors and start my day, as I like. It is really nice to live [at] home and manage these things on my own".

\section{Mobility as quality of life}

International research indicates that mobility and the ability to move around one's home is among the most important aspects in the quality of life for the elderly (Gabriel \& Bowling, 2004). Increased mobility for the elderly can refer to the capability of living in their homes longer. This reduces the need for care homes and saves society a lot of money (Hjorthol, Krogstad, \& Tennøy, 2013). Current research demonstrates that remaining in a familiar home and neighborhood tends to become more important as people age. If older people remain at home, they need to be able to go outdoors and continue to use their environment, including their local neighborhood; otherwise, they will be trapped inside. The outdoor environment is important not only in terms of independence, but also everyday experiences for the elderly. This includes social, physiological, and psychological health benefits (Inclusive Design for Getting Outdoors, 2008). 
Today Harald lives alone and has a visit from the home-care assistant once a week to dose his medicine. He also has access to an electric wheelchair and a chairlift, which helps him on a daily basis:

"When I got my electric wheelchair, as well as a chairlift in the main entrance, I could finally move around as I wanted to, both inside and outside. Now I take daily trips as much as I like, sometimes even several trips per day. Only when there is a lot of snow, it is hard for me to go for a trip. When that is the case, I sit outside on the stairs to get the daily amount of fresh air".

Even minimal encounters with nature, such as the view from the window, can be related to health benefits in context of hospitals, prisons, workplaces, and home environments. Natural areas can be both attractive and restorative. They encourage outdoor activities and have the potential to make one's community safer and one's neighbors more reasonable. Natural areas have the capability to enhance exploration and understanding, as well as to facilitate meaningful action in the form of community participation (Kaplan \& Kaplan, 2003).

A study by Kono et al. (2004) investigated the relationship between the frequency of going outdoors among ambulatory frail elders living at home and the functional and psychosocial changes that followed. Data were collected via a questionnaire regarding activities of daily living, functional capacity, depression, self-efficacy, and social support. The elderly going outdoors were often less functionally impaired, more socially active, and less depressed than those going outdoors less often. The authors suggest that the frequency of going outdoors may be a useful indicator to predict positive changes in functional capacity, intellectual capacity, and self-efficacy among the elderly.

In 2008, the municipality built a walking trail around the water, just below Harald's house:

"When the weather is good, I drive all the way around the trail with my electric wheelchair. It is a good opportunity for me to meet other people and socialize, but the nicest thing about the pathway is that it goes into the woods. I really appreciate the woods. Both the air and the sounds in the woods are something special; it is comfortable. The woods are also full of varied impressions, which differ from others in normal daily life".

People who have access to nearby natural settings are healthier overall than other individuals. The long-term and indirect impact of nearby nature also includes increased levels of satisfaction with one's home and job and with life in general (Kaplan \& Kaplan, 1989). Natural surroundings are overrepresented among human beings' favorite places. They lead one away from daily life and help one to forget about stress and worry. Natural surroundings make one more relaxed and offer a lot of time to reflect on life (Korpela et al., 2001).

\section{Experiences of walking}

For Talbot and Kaplan's study “The benefit of nearby nature for elderly apartment residents" (1991), elderly residents from two apartment complexes were interviewed about the availability and importance of different nearby natural settings. The elderly were also asked how involved they were with various "nature compensation" indoor activities, such as watching nature programs or growing houseplants, which can be a substitute for more strenuous outdoor activities. The results from the study indicate that older adults consider access to nature near their homes a very important aspect. "Nature compensations" were frequently applied but did not affect satisfaction among the elderly. The study also showed that satisfaction levels were significantly higher among the elderly residents whose apartments overlooked natural settings or lived closer to certain kinds of outdoor setting (Talbot \& Kaplan, 1991).

Inclusive Design for Getting Outdoors (I'DGO) conducted a focus group interview in their project with elderly people aged 65 years and older to better understand the ways in which the outdoor environment relates to quality of life. The participants identified a number of ways in which access to the outdoor environment was beneficial in their quality of life: opportunity for meeting people and socializing; enjoyment of the outdoor environment, which refers to the fresh air, sunshine, gardening, and watching 
singing birds; good feelings or positive experience; and escape from indoors or from routine places. One of the participants mentioned that "being inside all the time is claustrophobic and boring [...] You get institutionalized if you don't get out".

Furthermore, I'DGO suggested three aspects related to the use of outdoor spaces: perception of supportiveness, pleasantness, and well-maintained open spaces. Perception of supportiveness means that if people perceive their open spaces as facilitating, rather than hindering, they are more likely to spend time outdoors with positive experience. Pleasantness refers to the provision of facilities and amenities, such as places furnished with benches and tables. Well-maintained open spaces make it more attractive to spend time outdoors and to be physically active or just to watch nature. The inaccessibility of many outdoor environments is a major problem that affects the elderly. This is further aggravated by a lack of awareness about design features that could support independent activities and make a difference to the quality of daily life.

\section{Facilitating access to nature}

"Walking strategy for older citizens - knowledge base for planning in Kristiansand" (Norway) is another project concerning the elderly and their possibility for moving outdoors (Hjorthol, Krogstad, \& Tennøy, 2013). The project wanted to provide a basis for development of a walking strategy for the elderly, which made it more attractive and safer for them to walk outdoors. The elderly themselves were included and listened to throughout all stages of the project to better understand their needs. Walking is both a physically and psychologically healthy pursuit, especially for the elderly. There is a good chance to meet with acquaintances in the street, whereas the perception of the environment differs in a positive way from motorized transport. Improved outdoor conditions for older citizens would increase their mobility, bring positive health effects, and also reduce the need for motorized transport, which is a positive contribution to environment, besides increased health benefits.

Participants in the project mentioned several favorite measures, such as green vegetation, satisfactory winter maintenance, good lighting, safety, and sitting facilities along the way. Also, specialized walking and cycling paths in summer, reduced traffic volumes in the most frequently used pedestrian areas, lower speed limits in central areas, wider pavements, and lowered curbs are all measures that, if improved, would lead to increased activity for older citizens. As motivations for walking, people referred to the joy of being out in the fresh air, health effects, recreation, and nature experience, target points in the neighborhood, and socializing. Barriers, on the other hand, were weather and winter conditions, bad health, feeling of unsafe, and lack of a walking companion.

The project in Kristiansand also demonstrated the need for inter-sectional action at the municipal level and for coordination at various levels in the public administration. The authors concluded that by increasing the physical arrangements and low threshold services, one could increase the activity of older people. They also stated that it was important to give information about activities and establish walking groups to motivate older people to walk more, especially those without a companion to walk with.

\section{Dimensions of sociality}

Harald appreciates socializing with others, and every Wednesday he goes to a "Pensjonistkafé", where retired people get together.

"It is very nice to meet old friends and talk about things from both nowadays and earlier in life. I am aware that my mobility is a bit reduced, but at the café, I do not see myself as the disabled one. A lot of the people that come from the institutions and care homes seem dull. I am convinced that this has something to do with the lack of activity and fresh air. If these people were able to get daily trips outside like I do, they would have a much better life". 
When independent community-dwelling elderly people move from their homes to live in a residential care facility, the relation to nature and outdoors often undergoes a dramatic shift. For many of the elderly, their connection with the outdoors may strongly diminish or even disappear altogether (Stoneham \& Jones, 1997). The outdoor features and activities they previously enjoyed, such as their favorite garden, porch, or patio, are no longer available in the residential care facility. In addition, progressive physical impairment makes it difficult to access the outdoor environment, which is often more difficult than being indoor, considering walking surfaces, temperature, accessibility, etc. The loss of previously well-used spaces and the need for supportive-designed elements make it increasingly crucial for landscape designers to identify and address the actual needs of the elderly in the outdoor space in a number of diverse residential settings (Rodiek \& Schwarz, 2006).

\section{Viewing nature}

For their study "The effect of viewing a landscape on physiological health of elderly woman", Tang \& Brown (2006) measured the blood pressure and heart rates of elderly women who spent time looking at a natural landscape. The study showed that viewing the natural landscape resulted in lower systolic and diastolic blood pressure and in lower heart rates among the women who were watching the natural landscape compared to those of the women in the control group, who had no outdoor view. The authors believed that the results were highly important for the design of residential housing for the elderly and should be taken in consideration.

In their study "Healthy nature healthy people: 'Contact with nature' as an upstream health promotion intervention for populations", Maller et al. (2006) made a broad summary of various evidence, supporting the assertion that contact with nature promotes health and well-being. The statements are as follows:

1. Beneficial physiological effects occur when humans encounter, observe, or interact with animals, plants, landscape, or wilderness;

2. Natural environments foster recovery from mental fatigue and are restorative;

3. When given a choice, people prefer natural environments (particularly those with water features, large old trees, intact vegetation, or minimal human influence) to urban ones, regardless of nationality or culture;

4. Exposure to natural environments enhances the ability to cope with and recover from stress and from illness and injury;

5. Observing nature can restore concentration and improve productivity;

6. Having nature in close proximity, or just knowing it exists, is important to people regardless of whether they are regular "users" of it;

7. People have a more positive outlook on life and higher life satisfaction when in proximity to nature.

All these positive statements are good reasons to favor nature as a resource for the human being. Natural environments have a broad appeal, yet they do not require extensive exposure. The outdoors has multiple favorable influences in relation to the elderly and should be seen as both a mental and a physical resource. For Harald, it was the best medicine of all:

"I felt the amazing warmth and energy from the sun. I watched the green meadow blowing gently in the wind. I heard the birds singing, and I could smell the fresh scents of spring in the air. That feeling is the most wonderful thing I have ever experienced. I was moved to tears". 


\section{REFERENCES}

Adams, J.M., \& White, M. (2004). Biological ageing-A fundamental, biological link between social-economic status and health? European Journal of Public Health, 14(3), 331-334.

Bergman, L.M. (2012). Overvekt of fedme blant eldre: hva betyr helse- og friluftslivsverdier, personlig kontroll og fysisk aktivitet? /Overweight of obesity among the elderly: what does health and outdoor recreation values, personal control and physical activity?/. Master's thesis, University of Oslo in Oslo, Norway. Retrieved March, 11, 2015, from https://www.duo.uio.no/bitstream/handle/10852/35192/MariexL.xBergman.pdf?sequence=2

Bischoff, A., Marcussen, J., \& Reiten, T. (2007). Friluftsliv og helse - en kunnskapsoversikt /Outdoors and health knowledge overview/. Bø, Norway: Høgskulen i Telemark.

Gabriel, Z., \& Bowling, A. (2004). Quality of life from the perspective of older people. Aging and Society, 24(5), 675691.

Hjorthol, R., Krogstad, R.J., \& Tennøy, A. (2013). Gåstrategi for eldre - kunnskapsgrunnlag for planlegging $i$ Kristiansand /Walking strategy for seniors - knowledge for planning in Kristiansand/. TØI rapport 1265/2013. Oslo, Norway: Transportøkonomisk institutt. Retrieved March, 11, 2015, from https:/www.toi.no/getfile.php/Publikasjoner/TØI\%20rapporter/2013/1265-2013/1265 hele\%20rapporten\%20nett.pdf

Inclusive Design for Getting Outdoors. (2008). How does the outdoor environment affect older people's quality of life? Retrieved March, 11, 2015, from http://www.idgo.ac.uk/older_people_outdoors/outdoor_environment_qol.htm

Jin, K. (2010). Modern biological theories of aging. Aging and Disease, 1(2), $72-74$.

Kaplan, R., \& Kaplan, S. (1989). The experience of nature: A psychological perspective. Cambridge, England: Cambridge University Press.

Kaplan, R. \& Kaplan, S. (2003). Health, supportive environments, and the reasonable person model. American Journal of Public Health, 93(9), 1484-1489.

Kono, A., Kai, I., Sakato, C., \& Rubenstein, L.Z. (2004). Frequency of going outdoors: A predictor of functional and psychosocial change among ambulatory frail elders living at home. Journal of Gerontology, Series A: Medical Sciences, 59(3), 275-280.

Korpela, K.M., Hartig, T., Kaiser, F.G., \& Fuhrer, U. (2001). Restorative experience and self-regulation in favorite places. Environment \& Behavior, 33(4), 572-589.

Lawton, M. P. (1986). Environment and aging. Albany, NY: Center for the Study of Aging.

Maller, C., Townsend, M., Pryor, A., Brown, P., \& Leger, L. (2006). Healthy nature healthy people: 'Contact with nature' as an upstream health promotion intervention for populations. Health Promotion International, 21 (1), 45-54.

Rodiek, S., \& Schwarz, B. (2006). Resident perceptions of physical environment features that influence outdoor usage at assisted living facilities. Journal of Housing for the Elderly, 19(3-4), 95-107.

Stoneham, J., \& Jones, R. (1997). Residential landscapes: Their contribution to the quality of older people's lives. Activities, Adaptation \& Aging, 22(1-2), 17-26.

Talbot, J.F., \& Kaplan, R. (1991).The benefits of nearby nature for elderly apartment residents. International Journal of Aging and Human Development, 33(2), 119-130.

Tang, J.W., \& Brown, R.D. (2006). The effect of viewing a landscape on physiological health of elderly women. Journal of Housing for the Elderly, 19(3-4), 187-202.

AUTHOR'S ADDRESS:
Linn Terese Ramsland

University of Rome "Foro Italico"

Plazza Lauro De Bosis

15, 00135 Roma, Italy

Email: linntereseramsland@ outlook.com 